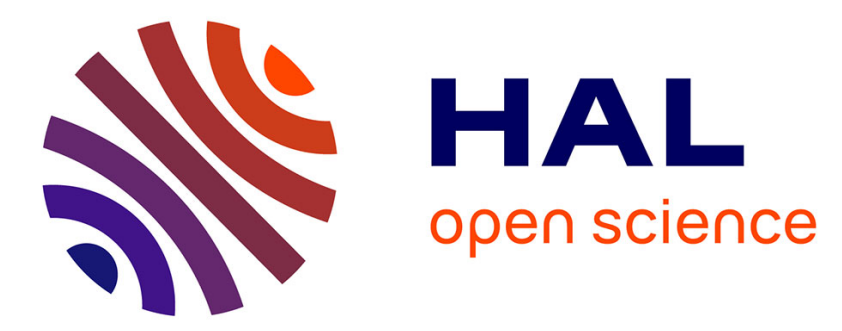

\title{
Monitoring Coseismic Temporal Changes of Shallow Material during, Strong Ground Motion with Interferometry and Autocorrelation
}

\author{
Luis Fabian Bonilla, Philippe Gueguen, Yehuda Ben-Zion
}

\section{To cite this version:}

Luis Fabian Bonilla, Philippe Gueguen, Yehuda Ben-Zion. Monitoring Coseismic Temporal Changes of Shallow Material during ,Strong Ground Motion with Interferometry and Autocorrelation. Bulletin of the Seismological Society of America, 2019, 109 (1), pp.187-198. 10.1785/0120180092 hal-03233577

\section{HAL Id: hal-03233577 \\ https://hal.science/hal-03233577}

Submitted on 25 May 2021

HAL is a multi-disciplinary open access archive for the deposit and dissemination of scientific research documents, whether they are published or not. The documents may come from teaching and research institutions in France or abroad, or from public or private research centers.
L'archive ouverte pluridisciplinaire HAL, est destinée au dépôt et à la diffusion de documents scientifiques de niveau recherche, publiés ou non, émanant des établissements d'enseignement et de recherche français ou étrangers, des laboratoires publics ou privés. 


\title{
Monitoring Coseismic Temporal Changes of Shallow Material during Strong Ground Motion with Interferometry and Autocorrelation
}

\author{
by Luis Fabian Bonilla, Philippe Guéguen, and Yehuda Ben-Zion
}

\begin{abstract}
Temporal changes of seismic velocities generated at the subsurface by the $2011 M_{\mathrm{w}} 9$ Tohoku earthquake in Japan are analyzed using interferometry and autocorrelation of waveforms recorded by surface and borehole sensors at the KiK-net station IBRH16. Spectral ratios and interferometry of data recorded in moving time windows at the surface and a depth of $300 \mathrm{~m}$ exhibit clear time delays and reduction of the predominant frequency during the strong ground motion followed by partial recovery in the waveform coda. Converting the time-delay evolution to velocity changes implies about $30 \%$ velocity reduction in the structure between the two sensors. Calculating temporal evolution with autocorrelation of data at the surface sensor in the moving time window indicates about $50 \%$ velocity reduction, reflecting changes of shallower material below the station. Computing autocorrelations of data recorded by the surface sensor with the Stockwell transform allows monitoring temporal changes with higher resolution that approaches the sampling rate of the waveforms. Using this technique, we estimate about $60 \%$ drop of seismic velocity below the surface sensor during strong ground motion followed again by partial recovery in the coda. These results provide fundamental information on in situ dynamic properties of soils and damaged shallow rocks that complement laboratory measurements, with important implications for constitutive equations of material degradation and healing and nonlinear site effects.
\end{abstract}

Electronic Supplement: Figures showing time-delay and predominant frequency evolution for Tohoku aftershocks.

\section{Introduction}

Solids with cracks and other defects referred to collectively as damage exhibit nonlinear elasticity manifested by shifts of the resonance frequency with increasing loading amplitude and related phenomena (e.g., Johnson and Jia, 2005; Lyakhovsky et al., 2009; Guéguen et al., 2016; Remillieux et al., 2017). If the loading amplitude exceeds a threshold that depends on the material, existing damage, confining pressure, and other conditions, the material fails, and the damage increases (e.g., Lockner et al., 1977; Pasqualini et al., 2007). This leads to reduced seismic velocities and related changes to other material properties such as anisotropy and attenuation (e.g., Dresen and Gueguen, 2004; Hamiel et al., 2009). During time intervals when the stress is below the failure threshold, healing of damage and recovery of seismic velocities and related properties occur. In situ analyses of nonlinear rock behavior and temporal changes of seismic properties are important for improved understanding of wave propagation effects and the effective rheology in the shallow crust, estimating seismic shaking hazard and other topics.
In recent years, time-lapse analysis by cross correlation and interferometry of ambient seismic noise has been used extensively to characterize small changes of seismic velocities in various tectonic regions (e.g., Sens-Schönfelder and Wegler, 2006; Brenguier et al., 2008, 2014). However, using ambient noise requires a wavefield that is equipartitioned or fully diffused (e.g., Weaver and Lobkis, 2004; Wapenaar et al., 2011). To satisfy this condition, earthquakes and other impulsive signals are removed from the records before analysis (Bensen et al., 2007). This precludes analysis of changes associated with strong seismic ground motion. Also, noisebased studies typically use timesteps of days or more because stacking is required to increase the signal-to-noise ratio of the weak diffuse field. Monitoring nonlinear behavior and temporal changes of properties with earthquake waveforms can achieve time resolution of minutes to seconds and resolve large temporal changes (e.g., Sawazaki et al., 2006; Wu et al., 2009, 2010; Nakata and Snieder, 2012).

Likewise, for data recorded at a single station, autocorrelation of earthquake waveforms can be used to recover 

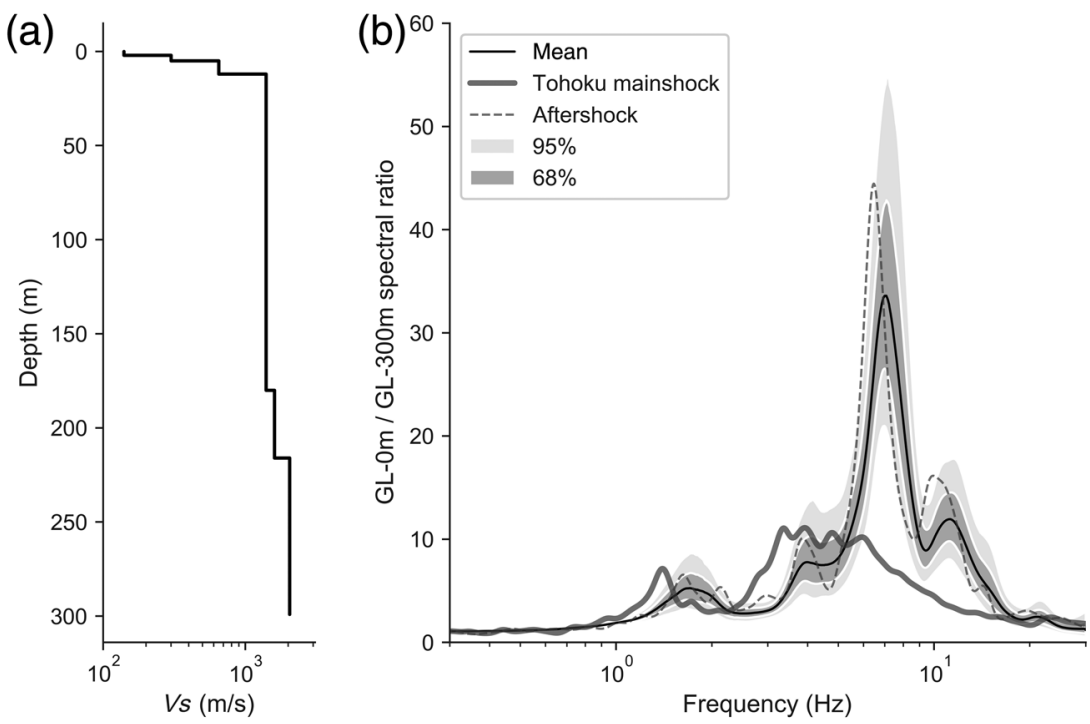

Figure 1. (a) Shear-wave velocity profile for KiK-net station IBRH16. (b) Spectral ratios between stations at the surface and $300 \mathrm{~m}$. The reference spectral ratio is computed using records with peak ground acceleration (PGA) less than $0.1 \mathrm{~m} / \mathrm{s}^{2}$ at the surface. The solid line is the mean amplification, and the dark and light shaded areas represent the $68 \%$ and $95 \%$ confidence limits, respectively (modified from Bonilla et al., 2011). In addition, the thick solid line is the spectral ratio using Tohoku mainshock data, and the dashed line is the amplification computed using the aftershock records (Table 1). event producing weak motion. The computed temporal changes of seismic velocities in the subsurface material during the strong motion of the Tohoku earthquake are in the 30\%-60\% range. We finish comparing results obtained with different techniques and sensor configurations and discussing implications to rheology of the shallow crust and earthquake engineering.

\section{Data and Methods}

In the following, we analyze data recorded at the KiK-net station IBRH16. This station has one sensor at GL-0m and another at GL-300m; the corresponding shear-wave velocity profile is given in Figure 1a (Okada et al., 2004). This velocity model predicts a travel time of $0.218 \mathrm{~s}$ from 300-m depth to the surface. The associated $V_{S 30}$ (i.e., harmonic average shearwave velocity in the first $30 \mathrm{~m}$ ) is $626 \mathrm{~m} / \mathrm{s}$, which can be considered as stiff soil. However, the top $5 \mathrm{~m}$ has veloc-

the zero-offset reflection seismogram beneath the site (Claerbout, 1968). This method has been used to image local subsurface structures with microearthquake data (e.g., Scherbaum, 1987; Daneshvar et al., 1995). Nakahara (2014) computed and stacked autocorrelation functions (ACFs) using the coda of earthquake waveforms recorded by KiKnet stations to map local velocity changes caused by the 2011 $M_{\mathrm{w}} 9.0$ Tohoku event. Sawazaki et al. (2016) worked on seismic noise recorded at Hi-net stations to study velocity changes induced by the $2014 M_{\mathrm{w}} 6.2$ northern Nagano Prefecture earthquake, and Seggern and Anderson (2017) studied velocity variations in a fault zone produced by an $M_{\mathrm{w}} 5.0$ earthquake that struck Nevada in 2008. As in the case of noise correlation techniques, the use of microearthquakes, coda, and ambient seismic noise often requires stacking the ACFs to enhance the signal-to-noise ratio, therefore losing time resolution in the estimated velocity changes.

In the present study, we analyze temporal changes of seismic velocities in the subsurface material using interferometry and autocorrelation of earthquake waveforms recorded by two instrument configurations. The first involves a pair of sensors, one at the surface and the other at depth, and is illustrated with data from the KiK-net borehole station IBRH16 in Japan. The second configuration is the common situation of a single sensor located at the surface and is illustrated by the surface sensor of the KiK-net borehole. In what follows, we describe the data and methods, focusing first on the borehole configuration and then on single surface data. The results are illustrated using waveforms generated by the $2011 M_{\mathrm{w}} 9.0$ Tohoku earthquake in Japan and a smaller ities lower than $300 \mathrm{~m} / \mathrm{s}$ overlaying stiff material $\left(V_{S}>650 \mathrm{~m} / \mathrm{s}\right)$. The combination of low-velocity layers close to the surface and a relatively strong impedance contrast may favor nonlinear soil behavior in case of strong ground shaking caused by the joint effect of low soil strength and wave amplification, respectively (Bonilla et al., 2011; Régnier et al., 2013). Figure 1b displays the spectral ratio between these two sensors using data recorded between 1998 and 2009 having peak ground acceleration (PGA) values less than $0.1 \mathrm{~m} / \mathrm{s}^{2}$ at the surface (Bonilla et al., 2011). We assume that such weak ground motion does not induce nonlinearity and temporal changes of velocities, so the behavior in Figure 1b can serve as a reference response for this site. The response shows that the fundamental and predominant frequencies are 1.8 and $7 \mathrm{~Hz}$, respectively.

As a case study with strong temporal changes, we analyze acceleration time histories generated by the 2011 $M_{\mathrm{w}}$ 9.0 Tohoku earthquake (Table 1). For comparison, we also examine data generated by an aftershock with $M_{\mathrm{JMA}} 4.5$. The PGAs recorded in the east-west component of the surface sensor are $5.85 \mathrm{~m} / \mathrm{s}^{2}$ for the Tohoku earthquake and $0.106 \mathrm{~m} / \mathrm{s}^{2}$ for the aftershock. Figure $1 \mathrm{~b}$ also displays the spectral ratios obtained with these records. The Tohoku spectral ratio (thick line) presents a much lower amplification compared with the weak-motion estimate, being outside of the 95\% confidence limits between 5 and $15 \mathrm{~Hz}$. Furthermore, there is a slight shift of the fundamental frequency (from 1.8 to $1.4 \mathrm{~Hz}$ ). Conversely, the spectral ratio using the aftershock data (dashed line) closely lies within the estimated $95 \%$ confidence limits, yet there is still a small

BSSA Early Edition 
Table 1

Characteristics of Earthquake Data Used in This Study (East-West Components)

\begin{tabular}{cccccc}
\hline File Name & Magnitude & Latitude $\left(^{\circ}\right)$ & Longitude $\left(^{\circ}\right)$ & Epicentral Distance $(\mathrm{km})$ & PGA $\left(\mathrm{m} / \mathrm{s}^{2}\right)$ \\
\hline IBRH161103111446 & 9.0 & 38.1 & 142.8 & 271.8 & 5.85 \\
IBRH161103121014 & 4.5 & 37.3 & 141.4 & 115.4 & 0.106 \\
\hline
\end{tabular}

PGA, peak ground acceleration.

shift of the predominant frequency compared with the reference response.

In the next three subsections, we describe how to estimate velocity changes between two sensors in a vertical array using seismic interferometry and how to measure changes below individual sensors using autocorrelation. In particular, we propose a new method to study the evolution of nonlinear soil behavior using nonstationary earthquake signals using a Stockwell autocorrelation-based approach.

\section{Seismic Interferometry}

Consider two receivers in a borehole configuration with one sensor at the surface and the other at depth. The initial shear-wave propagation speed $v_{0}$ between the surface and depth $H$ is defined as $H / t_{0}$, in which $t_{0}$ is the travel time. A changed medium velocity $v$ is given by $H / t$ with $t$ being the current travel time. The time difference $\Delta t=t-t_{0}$ is $\Delta t=H\left(v_{0}-v\right) /\left(v_{0} v\right)$. From this and denoting the velocity change by $\Delta v=v-v_{0}$, we have $\Delta t / t=-\Delta v / v_{0}$ (e.g., Poupinet et al., 1984).

The response of two receivers located at $x=x_{A}$ and $x=$ $x_{B}$ to a source located at $x=x_{S}$ can be written in the frequency domain as $u\left(x_{A}, x_{S}, \omega\right)$ and $u\left(x_{B}, x_{S}, \omega\right)$, respectively. The deconvolved wavefield between the two receivers $D_{B-A}(\omega)$ is given in the frequency domain by the ratio

$$
D_{B-A}(\omega)=\frac{u\left(x_{B}, x_{S}, \omega\right)}{u\left(x_{A}, x_{S}, \omega\right)} .
$$

The ratio $D_{B-A}(\omega)$ is a complex valued number, and its norm is referred to as the transfer function between receivers $A$ and $B$. The time-domain representation of equation (1a) gives the impulse response function (IRF) between the receivers. In practice, the division in equation (1a) may present instability problems because the denominator may have values close to zero at certain frequencies. To improve the numerical estimation of equation (1a), we multiply both the numerator and denominator by the complex conjugate of $u\left(x_{A}, x_{S}, \omega\right)$, leading to

$$
D_{B-A}(\omega)=\frac{u\left(x_{B}, x_{S}, \omega\right) u^{*}\left(x_{A}, x_{S}, \omega\right)}{\left|u\left(x_{A}, x_{S}, \omega\right)\right|^{2}},
$$

in which $\left|u\left(x_{A}, x_{S}, \omega\right)\right|^{2}$ is the power spectra of the wavefield in $x_{A}$ (e.g., Wapenaar et al., 2010).

The deconvolution in equation (1b) still has potential instabilities due to near-zero values in the power spectra. To reduce this problem, we smooth the Fourier spectra computations using the multitaper method (Prieto et al., 2007). In addition, a regularization constant $\epsilon=1 \%$ of the average of the power spectra is added to ensure nonnull values in the denominator (Wapenaar et al., 2010; Nakata and Snieder, 2012). With this, we have

$$
D_{B-A}(\omega)=\frac{u\left(x_{B}, x_{S}, \omega\right) u^{*}\left(x_{A}, x_{S}, \omega\right)}{\left|u\left(x_{A}, x_{S}, \omega\right)\right|^{2}+\epsilon} .
$$

Transforming the ratio $D_{B-A}(\omega)$ in equation (1c) with a regularization constant $\epsilon$ to the time domain gives the IRF between receivers known as seismic interferometry.

\section{Earthquake Autocorrelation Functions}

Following Claerbout (1968), a reflection seismogram can be obtained from the autocorrelation of earthquake waveforms recorded at a site. To have an homogeneous signal processing for both seismic interferometry and autocorrelation, we compute the ACFs in the frequency domain (product of Fourier spectrum of the signal with its complex conjugate) using the multitaper library of Prieto et al. (2007) and then go back to the time domain using the inverse Fourier transform.

Seismic interferometry and ACFs are computed on short time windows. This allows tracking the time evolution of the resulting time delays, which are correlated to the velocity changes of the subsurface during the earthquake ground motion. This can also be seen as short-time impulse response and ACFs, respectively. However, in some cases, it is necessary to increase the time resolution of such estimates. This can be done with the use of time-frequency analysis, which is explained next.

\section{Earthquake Instantaneous Autocorrelation Functions}

The Stockwell transform (ST) is a multiresolution operator that represents a time series in a time-frequency domain (Stockwell et al., 1996). Given a 1D function $h(t)$, its ST is defined as

$$
S(\tau, f)=\int_{-\infty}^{\infty} h(t) w(\tau-t, f) e^{-i 2 \pi f t} \mathrm{~d} t .
$$

The window $w(\tau, f)$ is associated with a Gaussian function as

$$
w(\tau, f)=\frac{|f|}{k \sqrt{2 \pi}} e^{\frac{-\tau^{2} f^{2}}{2 k^{2}}},
$$


in which $f$ is the frequency and $t$ and $\tau$ are time variables The scaling factor $k$ is introduced in the formulation of the generalized ST (e.g., Sahu et al., 2009) and controls the number of oscillations in the window. In this article, this value is set to 3 for all computations. The ST decomposes a signal into temporal $(\tau)$ and frequency $(f)$ components using a Gaussian window whose width is inversely proportional to its center frequency $f$. Thus, low frequencies have wider Gaussian windows than higher frequencies.

The relation between $S(\tau, f)$ and the Fourier transform of $h(t)$ noted as $H(f)$ is

$$
H(f)=\int_{-\infty}^{\infty} S(\tau, f) \mathrm{d} \tau
$$

The representation of the Stockwell decomposition over time yields the Fourier coefficients of the signal (complex values). Multiplying the ST by its complex conjugate and taking, at each timestep, the inverse Fourier transform of the product, we obtain what we call the instantaneous ACFs. The time delays computed in this way have the same sampling rate of the signal, providing high resolution of the related velocity changes beneath the station.

Time Evolution of Predominant Frequency and Spectral Bandwidth

For a real valued time series, the Fourier spectrum can be fully represented on the positive frequency axis. Computing the associated power spectrum $P(f)$, the predominant frequency $f_{p}$ and spectral bandwidth $f_{b}$ are defined as (Cohen, 1989)

$$
\begin{gathered}
f_{p}^{2}=\frac{\int_{0}^{\infty} f^{2} P(f) \mathrm{d} f}{\int_{0}^{\infty} P(f) \mathrm{d} f} \\
f_{b}=\frac{\int_{0}^{\infty}\left(f-f_{c}\right)^{2} P(f) \mathrm{d} f}{\int_{0}^{\infty} P(f) \mathrm{d} f},
\end{gathered}
$$

in which $f_{c}$ is the central frequency

$$
f_{c}=\frac{\int_{0}^{\infty} f P(f) \mathrm{d} f}{\int_{0}^{\infty} P(f) \mathrm{d} f} .
$$

Equations (5) and (6) allow computing the predominant frequency and related variance, which describe the spectral characteristics of a signal. These equations are then applied to either the short time windows or ST estimates of the cross-correlation functions and ACFs to obtain the time evolution of the predominant frequency and its variance of nonstationary signals.

\section{Results}

\section{Analysis of Surface and Borehole Data}

We analyze the waveforms recorded at station IBRH16 generated by the $2011 M_{\mathrm{w}} 9.0$ Tohoku earthquake. Part of the analysis is to isolate the earthquake waveform from pre-event noise. This is done selecting the time series from the onset of the $P$ wave until the end of the signal. It is important to ensure the presence of long duration of the ground motion to have enough data to track the variations of time delays and predominant frequencies along the time history. We apply equation (1c) to moving time windows of 5.12-s length. At each time window, the mean of the time series is removed, and a Hanning taper of $2.5 \%$ is applied before computing the Fourier spectra with the multitaper method. We use $5.12 \mathrm{~s}$ because the differences between linear and nonlinear spectral ratios (Fig. 1b) are above $5 \mathrm{~Hz}$. Thus, a minimum resolution of $1 / 5.12 \mathrm{~Hz}(\sim 0.2 \mathrm{~Hz})$ is fine for this analysis. However, longer time windows will produce smoother velocity changes, and shorter ones will show faster variations, as discussed later. We select three 5.12-s time windows from the east-west acceleration time histories (Fig. 2a) associated with the beginning (A), during the strongest motion (B), and in the coda of the signal (C). Following Nakata and Snieder (2012), the signals are bandpassed between 1 and $12 \mathrm{~Hz}$ (where enough energy is observed in the spectral ratio of Fig. 1b) before and after deconvolution. The computed spectral ratios at these time windows are shown in Figure $2 \mathrm{~b}$ together with the $68 \%$ confidence limits reference response of Figure $1 \mathrm{~b}$ (gray shaded area). The initial part of the data (time window A) follows approximately the linear response. However, during the strong motion (time window B), the soil response is quite different with a strong deamplification and distortion of the spectral ratio. In the coda of the signal (time window $\mathrm{C}$ ), the response becomes closer to the linear case but with shifts of the resonance peaks to lower frequencies. Figure 2c illustrates the evolution of the IRF in the analyzed time windows. The maxima of the IRF between 0.2 and 0.4 s clearly indicate larger time delay during the strong motion and smaller delay at the coda. The initial value for time window $\mathrm{A}(0.22 \mathrm{~s})$ is very close to the computed travel time using the velocity model in Figure 1a. The results demonstrate the utility of the IRF for tracking velocity changes between two vertical array stations caused by strong motion. This was also shown in previous studies using the same type of analysis (e.g., Snieder et al., 2002; Wu et al., 2010; Wu and Peng, 2011; Nakata and Snieder, 2012). Furthermore, Todorovska and Trifunac (2008) applied a similar procedure to study the nonlinear response of the Van Nuys hotel using earthquakes recorded by the structure.

Figure 3 presents the evolution of the IRF calculated for the same records (Fig. 3a) using moving time windows that are $5.12 \mathrm{~s}$ long each and overlap by $80 \%$ (Fig. 3b). The predominant frequency and bandwidth calculated with equations (5) and (6) are shown in Figure 3c. The analysis provides a temporal resolution close to $1 \mathrm{~s}$ for a sampling rate of $100 \mathrm{~Hz}$. The IRF evolution clearly shows the increase of time delay as the ground motion increases and reduction to lower values when the motion amplitude decreases. The horizontal line in Figure $3 \mathrm{~b}$ represents the mean of time delays 

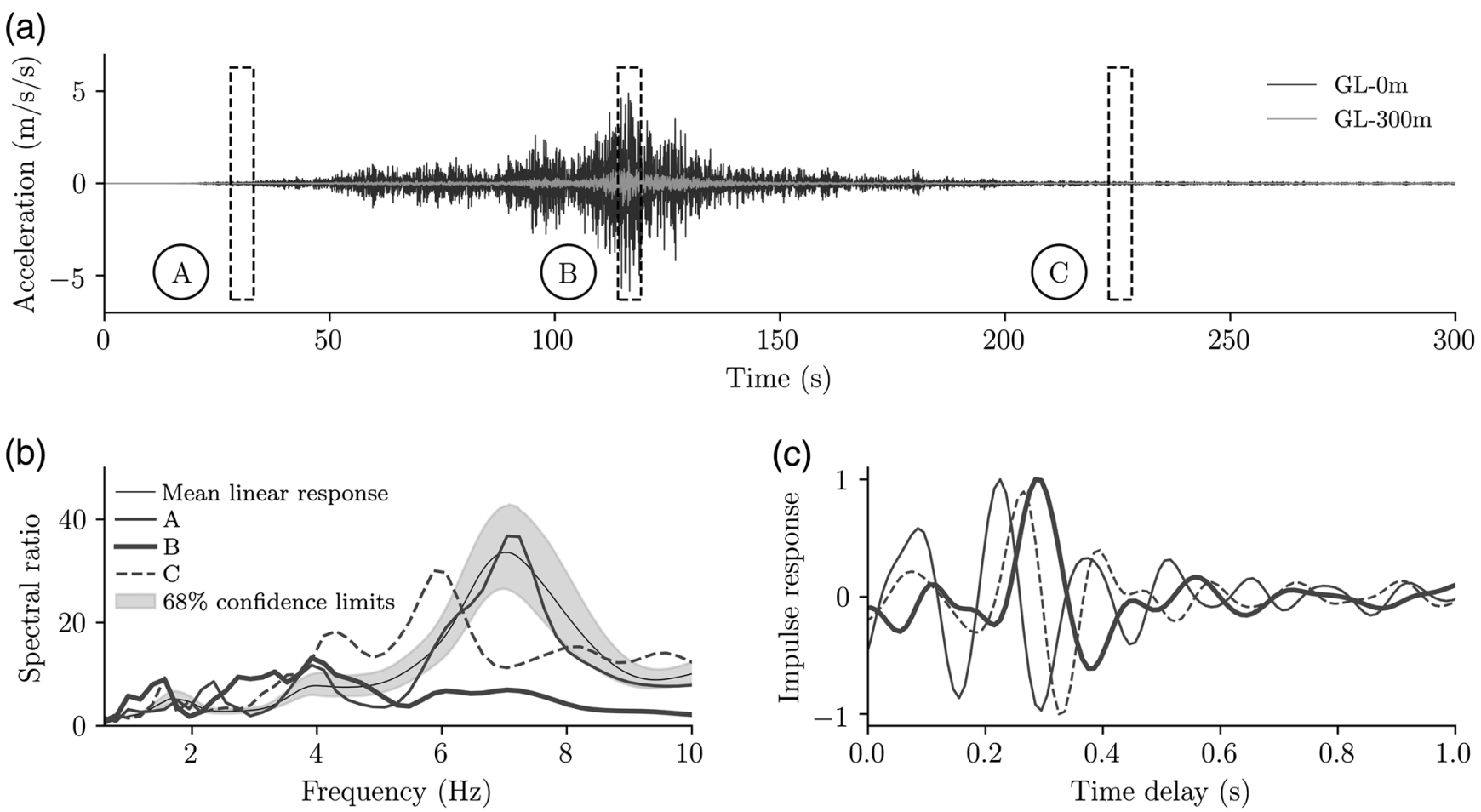

Figure 2. (a) East-west acceleration time histories recorded at station IBRH16 from the $2011 M_{\mathrm{w}} 9$ Tohoku earthquake. The sensors are separated $300 \mathrm{~m}$ between the surface and the borehole depth; GL, ground level. (b) Spectral ratios at different time windows. Solid line represents the response at time window A. Thick solid line indicates the response at time window B during the strongest motion. Dashed line shows the response at time window $\mathrm{C}$ in the coda of the signal. The linear response from Figure 1 is shown in gray. (c) The impulse response functions computed at the different time windows using equation (1c).

for acceleration values lower than $0.1 \mathrm{~m} / \mathrm{s}^{2}$, which provides a reference time delay for linear wave propagation. At the end of the record, the time delay is higher than the initial value, indicating that the recovery process remains incomplete. The predominant frequency has a clear anticorrelation with the time delay and is associated with frequency decrease during the strong motion (Fig. 3c). This is also clearly observed in the spectral ratio plotted in Figure 2b. We note that the predominant frequency around $7 \mathrm{~Hz}$ is strongly affected during the peak ground motion, whereas the fundamental frequency of $1.8 \mathrm{~Hz}$ is much less modified. This suggests that the velocity changes are mostly concentrated in the shallow section, as reported in studies using similar analyses (e.g., Sawazaki et al., 2006; Wu et al., 2009; Wu and Peng, 2011; Chandra et al., 2015) and comparisons between linear and nonlinear transfer functions (Bonilla et al., 2011; Régnier et al., 2013).

(E) Figure S1 (available in the electronic supplement to this article) shows the IRF evolution for an aftershock record having a PGA close to $0.1 \mathrm{~m} / \mathrm{s}^{2}$ (Table 1). In this example, we analyze the whole record, including pre-event noise, to test the method with low acceleration values. Some IRFs present relatively higher time delays between 40 and $50 \mathrm{~s}$ in the time series. However, they are not correlated to any strong phases in the records. These higher values may be related to the lower signal-to-noise ratio of these data. In average, we see no significant changes of the time delay and predominant frequency during ground motion. Furthermore, the computed time delays are close to those obtained at the end of the Tohoku record shown in Figure 3. This is probably because the soil is still perturbed several hours after the mainshock. We do not explore this phenomenon further, leaving it for a future study.

Having the time-delay evolution allows calculation of $\Delta t / t=-\Delta v / v_{0}$, with $\Delta t=t-t_{0}$ and $t_{0}$ being the reference time delay. The reference time delay is the average of time delays computed on time windows located before the PGA and having accelerations lower than $0.1 \mathrm{~m} / \mathrm{s}^{2}$. Obtaining $t$ requires picking the maxima of the IRF evolution (white line in Fig. 3b). Figure 4 shows the computed velocity changes (dots) and a smoothed loess version (black line) using a smoothing factor of 0.05 and three iterations. The highest velocity drop is during the time window having the strongest ground motion and is followed by a partial recovery late in the record. The results are quite stable, with just few outliers around $250 \mathrm{~s}$ for the computed velocity changes. Different options to compute the IRF maxima are discussed later, in the section of calculating surface data with higher temporal resolution.

\section{Analysis of Surface Data}

Here, we analyze the strong-motion data (Fig. 5a) recorded at the surface sensor of KiK-net station IBRH16 
(a)
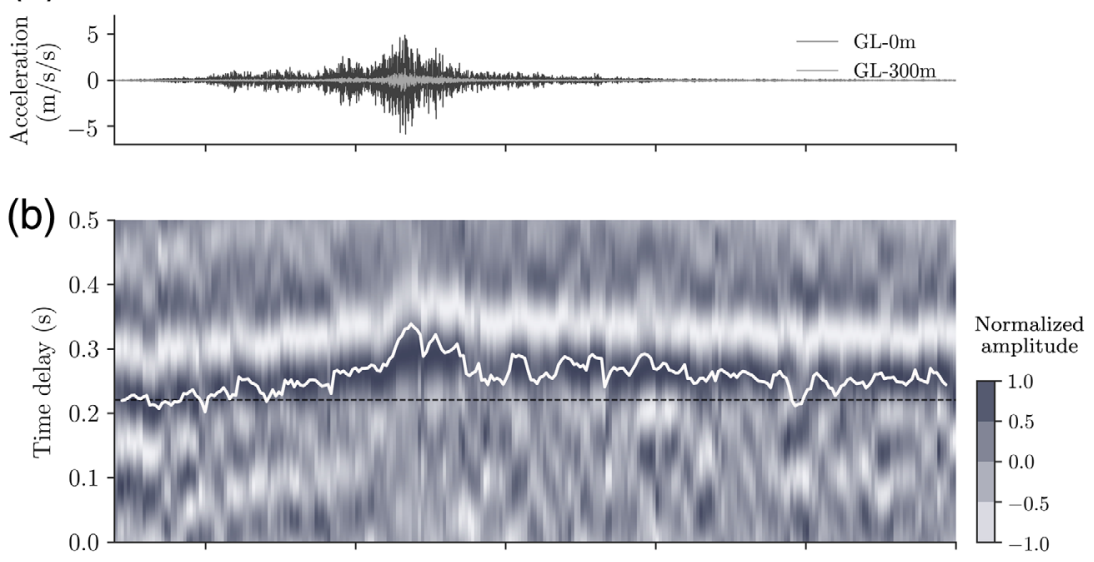

(c)

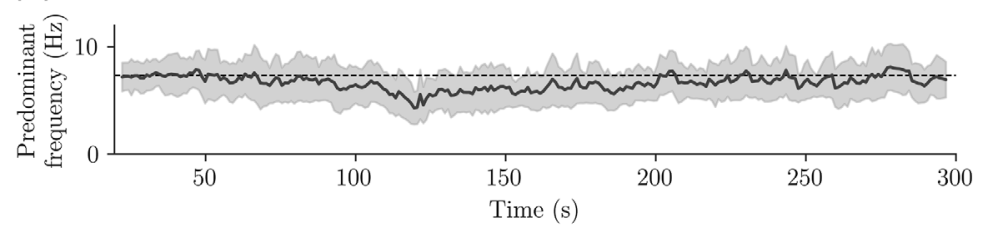

Figure 3. (a) Acceleration time histories recorded at GL-0m and GL-300m, respectively. (b) Time evolution of the impulse response computed in moving time windows; (c) predominant frequency and spectral bandwidth progress. The white solid line in (b) shows the maxima of the impulse response function (IRF) amplitude and represents the time-delay changes during the ground motion. These values become larger during the stronger part of the shaking. Conversely, the predominant frequency reaches its minimum at the same time. The color version of this figure is available only in the electronic edition.

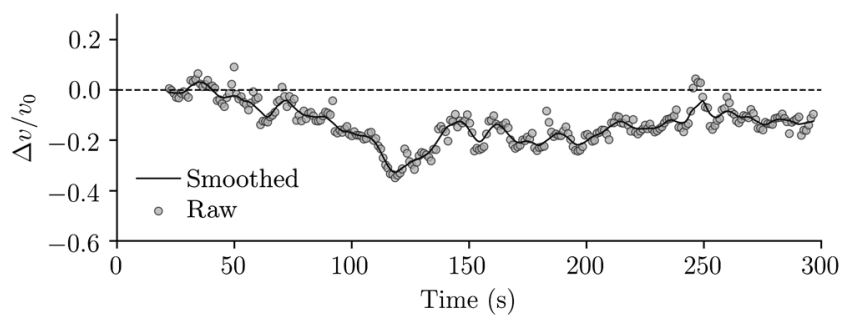

Figure 4. Velocity changes obtained from time-delay measurements on IRF estimates. Dots represent raw data, and black solid line shows a loess-smoothed version.

using autocorrelations. This is done because typically only surface records are available, and downhole data may also be heavily contaminated by the downgoing wavefield, making it difficult to interpret ACFs. As example, Sawazaki et al. (2016) used waveforms from Hi-net stations (downhole sensors) filtered between 1 and $3 \mathrm{~Hz}$, but data from the KiK-net stations were analyzed using frequencies between 1 and $10 \mathrm{~Hz}$.

To facilitate comparisons with the IRF calculations, we use the same time window length and overlapping sampling and compute the $\mathrm{ACF}$ of the surface signal at each time window. As before, mean removal and 2.5\% Hanning window tapering are implemented. The obtained evolution of the ACF and the corresponding predominant frequency are shown in Figure $5 \mathrm{~b}$ and $5 \mathrm{c}$, respectively. There is a clear increase of time delay during the strongest part of ground motion, reflecting reduction of seismic velocity in the subsurface material. As for results associated with the IRF, during the coda waves, there is partial recovery of the time delay. The predominant frequency shows the same behavior and very similar values to those in Figure 3.

The corresponding time evolution of velocity changes is computed as before and is shown in Figure 6. We note that the results associated with the ACF yield larger velocity drop compared with the IRF calculations as well as a faster recovery. (E) Figure S2 illustrates the ACF results on data associated with the aftershock used in the IRF computation. The computed time delays and associated predominant frequencies are relatively stable, and as in the case of the IRF results, the average values are also close to those found at the end of the Tohoku record (Fig. 5).

In this work, we use individual records to study the velocity changes induced by the ground motion. These changes are evaluated with respect to a reference value, which is defined for each record and ad hoc taken for acceleration values lower than $0.1 \mathrm{~m} / \mathrm{s}^{2}$ for times before the PGA. Thus, no absolute reference is computed. The dispersion of computed time delays using the aftershock records is quite low; however, this point of defining a threshold for nonlinear material response still needs to be assessed.

Computing IRF and ACF on moving time windows achieves high time resolution for tracking velocity changes of the subsurface material. However, in certain cases, it is needed to attain even higher time resolution. This is needed, for example, when estimating the recovery of material properties immediately after a velocity drop because the recovery process follows a $\log (t)$ evolution (e.g., Dieterich and Kilgore, 1996; Wu et al., 2009) with very fast changes near $t=0$. As illustrated in the next section, higher time resolution is possible when using the ST (Stockwell et al., 1996).

\section{Analysis of Surface Data with Higher Temporal Resolution}

Because the ST (equations 2 and 3) provides the amplitude and phase of the instantaneous wavelet that composes the signal, it can be used to compute the autocorrelation at each timestep. This allows us, in principle, to increase the 
(a)

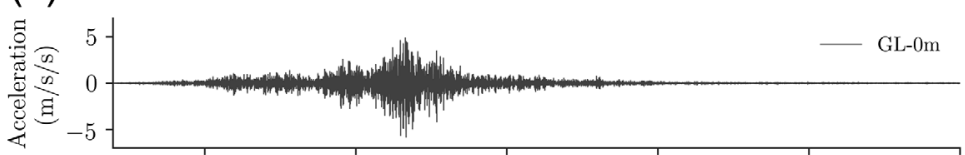

(b)

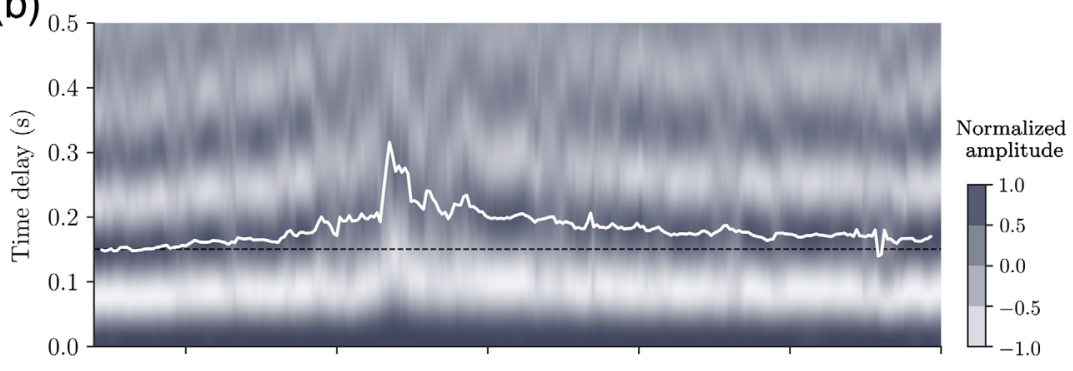

(c)

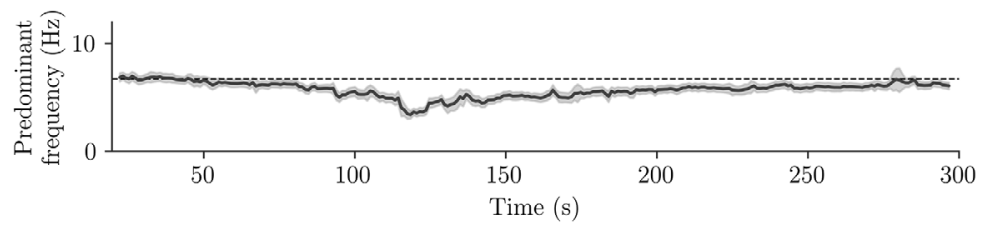

Figure 5. (a). Acceleration time history recorded at GL-0 m. (b) Time-delay evolution from autocorrelation function (ACF) computations on moving time windows. (c) Predominant frequency and spectral bandwidth progress. The color version of this figure is available only in the electronic edition.

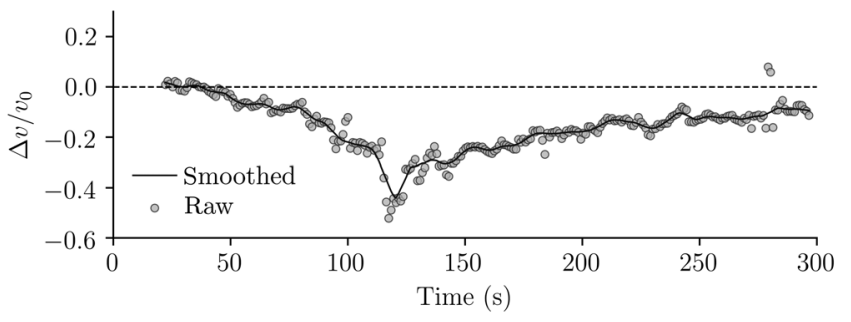

Figure 6. Velocity changes obtained from time-delay measurements on the ACF results. Dots represent raw data, and black solid line shows a loess-smoothed version.

time resolution from approximately $1 \mathrm{~s}$ in the examples shown above to $0.01 \mathrm{~s}$ when using the ST. However, computing the ST is quite costly in terms of CPU time and storage. Given the fact that Japanese records have an antialiasing filter at $30 \mathrm{~Hz}$, it is safe to downsample the data by a factor of 2. This leads to Nyquist frequency of $25 \mathrm{~Hz}$ and time resolution of $0.02 \mathrm{~s}$, which is still 50 times higher than in previous results. Figure 7 shows an example of velocity changes using the ST. The smoothing is done with the same loess smoothing parameters as in Figures 4 and 6.

The results using the ST show larger dispersion in both the predominant frequency and velocity changes than the moving time window counterparts. This dispersion comes from the fact that the ACF is computed at each timestep, so all oscillations in the data and corresponding spectral characteristics are mapped onto the ACF. For this reason, there are some velocity changes in Figure 7 that are outside the main tendency, in contrast to the smoother results using a moving time window of 512 samples. In other words, each moving time window used to estimate the ACF represents the average of 256 correlograms (because of the downsampling by a factor of 2) from the ST calculations. The ST-ACF calculations exhibit larger velocity changes (60\%) than those computed with the moving time window (50\%). This also implies that longer time windows will produce smoother estimates.

Instantaneous IRFs can also be computed using the ST. For example, Pianese et al. (2018) used this technique to study the nonlinear behavior of a building in Mexico. However, when dealing with soils, the deconvolution of wavelets with very different amplitudes (caused by the distance between sensors, noise in the signal, downgoing wave effect, and strong amplification near the surface) produces relatively noisy IRF at each timestep. This requires using better regularization techniques, which is outside the scope of this work.

As mentioned, the time-delay computations require picking the maxima of the evolving IRF and ACF (Figs. 3 and 5). We tried two methods. The first is simply a direct picking of maximal values of the correlograms. This works well for the ACF calculations with either moving time windows or the ST. The second method correlates the reference correlogram, calculated as the mean of the IRF or ACF for accelerations lower than $0.1 \mathrm{~m} / \mathrm{s}^{2}$ at times before the PGA, to all computed correlograms. An example of these two techniques is illustrated in Figure 8 for the ACF using the ST. As seen, the velocity change estimates may be different depending on the technique used, but the trends indicated by the smoothed black lines are almost the same. The direct picking of maxima (Fig. 8a) produces higher coseismic velocity drops, around $60 \%$, but using the correlation method produces fewer outliers and a smaller velocity drop of about $56 \%$ (Fig. 8b). The correlation method is preferred when computing IRF because the IRF correlograms are more complex than the ACF ones. More accurate estimates may be obtained using different techniques to find peaks of functions and filtering, which is not the purpose of this study.

Corresponding variations of the shear modulus $\mu$ can be obtained from the velocity changes $\Delta v=v-v_{0}$ readily (Fig. 9), as $v / v_{0}=1+\Delta v / v_{0}$, and the shear modulus is proportional to the square of velocity $\mu / \mu_{0} \approx\left(v / v_{0}\right)^{2}$. Because soft layers are close to the surface, the ratio $v(t) / V_{S 30}$, with $v(t)$ being the velocity time histories at the surface sensor, can be used as proxy for shear strain (Chandra et al., 2015, 2016; Guéguen, 2016). During strong 
(a)

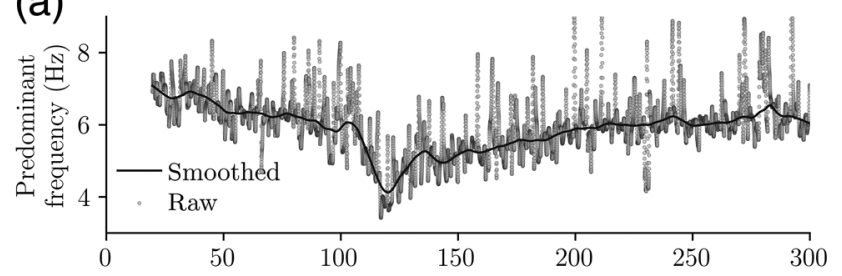

(b)

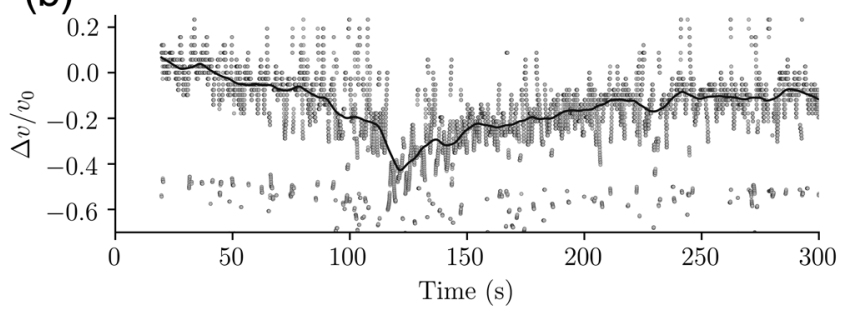

Figure 7. (a) Predominant frequency evolution. (b) Coseismic velocity changes. Both estimates use the Stockwell transform (ST) for computing ACF. Dots represent raw data, and black solid line shows a loess-smoothed version.

shaking, however, the instantaneous $V_{S 30}$ changes as shown earlier in this article and in other studies. Because we know $v / v_{0}$ as a function of time (i.e., Fig. 6), we correct $V_{S 30}$ to be $V_{S 30} \times v / v_{0}$.

Figure 9 provides estimated evolutions of shear strain and modulus using the smoother results based on moving time windows. Figure 9a,c shows the original and corrected shear-strain time history computed at station IBRH16. Because the IRF and ACF produce different velocity changes, the amplitude of the corrected shear strain is larger for the ACF result (Fig. 9c). Plotting the shear strain as a function of the normalized shear modulus at low strain values gives estimated shear modulus ratio close to 1 (Fig. 9b,d). For increasing shear deformation, the modulus decreases and has a minimum at the largest strain (largest acceleration). When the strong motion and deformation decrease, the shear modulus recovers in time. However, the recovery does not follow the same path as for low ground motion but is associated with hysteresis, indicating some degradation process. The ACF computations show larger degradation of the shear modulus down to 0.2 (Fig. 9d) compared with 0.5 for the IRF results (Fig. 9b), which implies a shear modulus reduction of $80 \%$ and 50\%, respectively. Ohmachi and Tahara (2011) found similar modulus reduction $(\sim 80 \%)$ and shear deformation $(0.1 \%)$ in their study of Aratozawa dam with a core having an average velocity of $500 \mathrm{~m} / \mathrm{s}$.

\section{Discussion}

The effects of the local geology on the duration, amplification, and spatial variability of earthquake ground motion are widely known. If the strength of the material is low and the ground shaking is sufficiently strong, nonlinear material behavior is triggered. Soil nonlinearity can be complex if
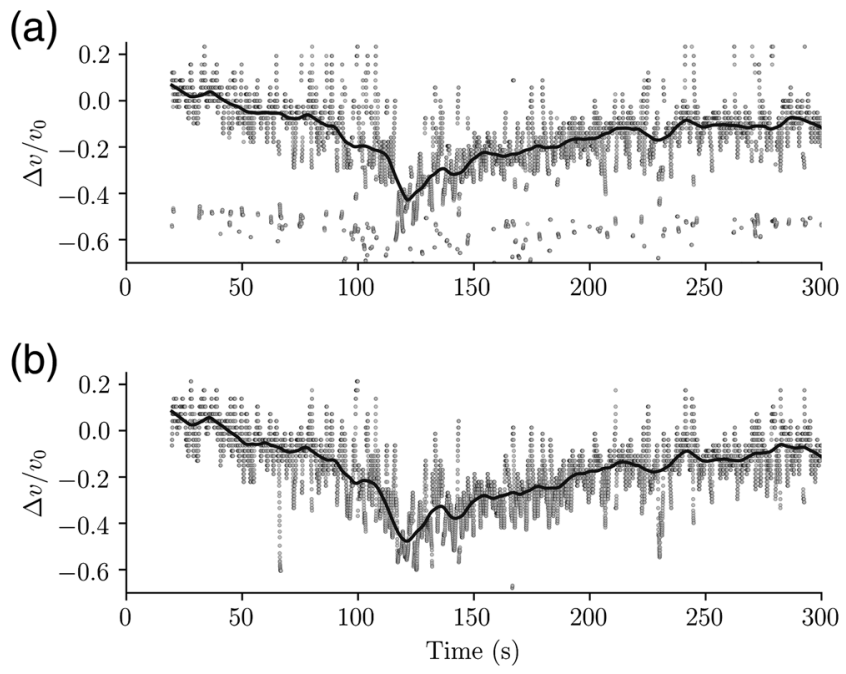

Figure 8. Velocity changes obtained from time-delay estimates of ACF using the ST. (a) Results from direct picking of maximum values of ACF. (b) Results from cross correlation. Dots represent raw data, and black solid line shows a loess-smoothed version.

changes of water pore pressure in saturated media are involved (Iai et al., 1995; Bonilla et al., 2005; Oral et al., 2017). These phenomena are included in studies of site effects. Temporal changes of properties of the local subsurface can significantly modify the site effects and may break the ergodicity hypothesis used in traditional seismic hazard analyses because the site term changes depending on the intensity of the ground motion. Do the statistics of a large strong ground-motion database produce stable results for these temporal changes? This is an open question that deserves more research. In this work, we present several techniques for quantifying temporal changes of seismic velocities in the shallow crust generated by strong seismic motion. Resolving small changes in time intervals not containing strong impulsive signals can be done well with time-lapse interferometry of ambient seismic noise (e.g., Brenguier et al., 2008; Rivet et al., 2011; Hillers et al., 2015). However, monitoring large and fast changes such as coseismic drops of seismic velocities in the shallow crust requires using earthquake waveforms (e.g., Sawazaki et al., 2006; Karabulut and Bouchon, 2007; Roux and Ben-Zion, 2014).

Moving time windows in earthquake waveforms generated by the $M_{\mathrm{w}} 9$ Tohoku earthquake and recorded at KiKnet borehole station IBRH16 in Japan are used to calculate the evolution of the IRF between the surface and borehole sensors. The results reveal about 30\% drop of shear-wave velocity in the top $300 \mathrm{~m}$ separating the two sensors during the passage of the strong ground motion of the Tohoku earthquake followed by a slow recovery (Fig. 4). Temporal changes in the more commonly available data of single stations are analyzed using ACFs in moving time windows. Calculating autocorrelations for the same data at the surface sensor of station IBRH16 yields about 50\% coseismic drop 
(a)

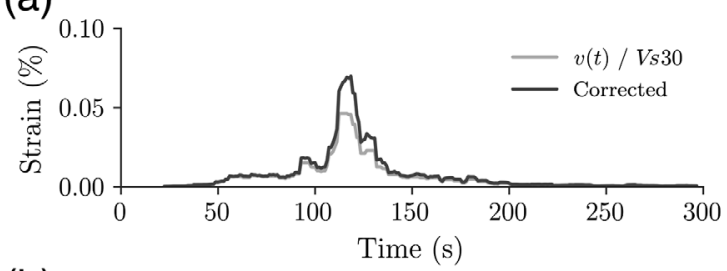

(b)

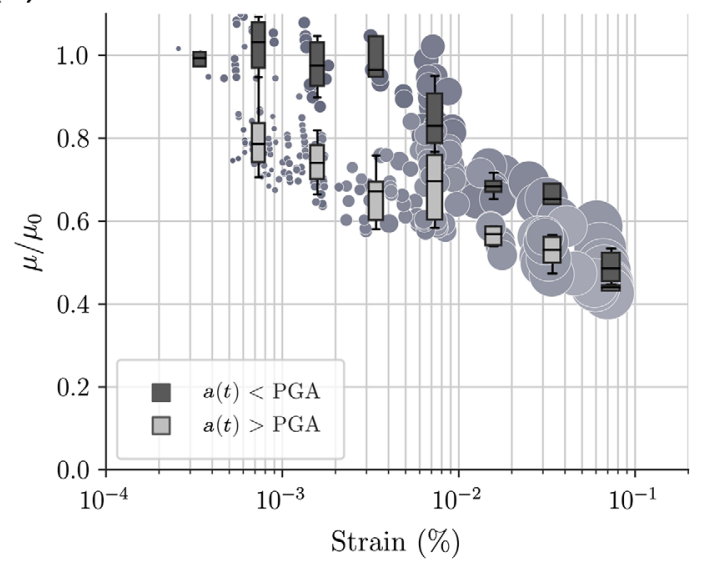

(c)

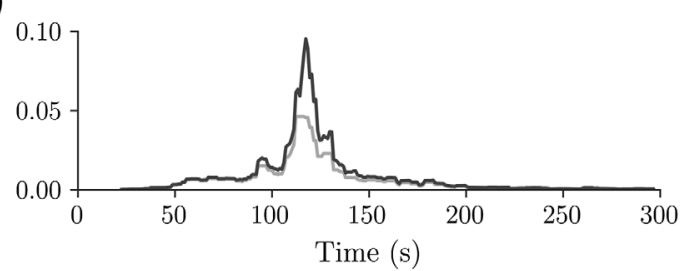

(d)

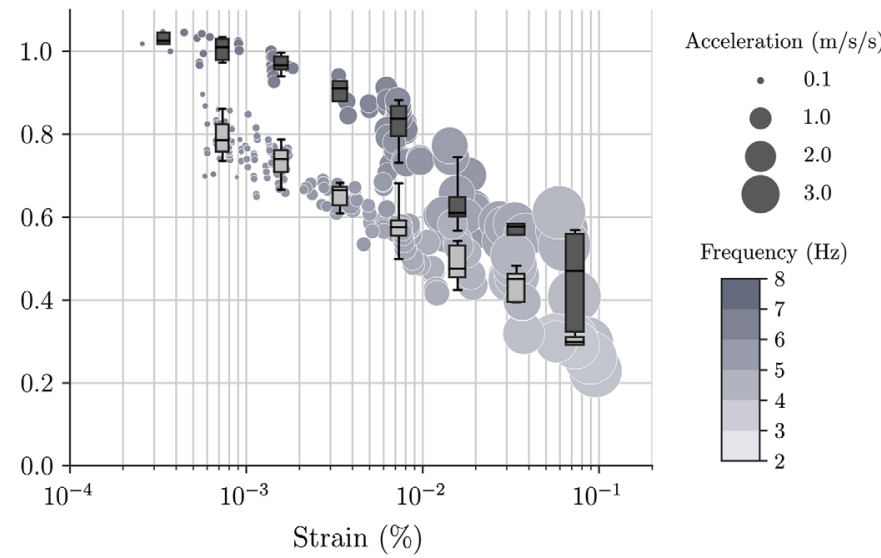

Figure 9. Corrected shear strain for velocity changes obtained from (a) IRF and (c) ACF, respectively. Shear modulus degradation as a function of shear strain using (b) IRF and (d) ACF estimates. Note that larger acceleration/deformation values are associated with lower predominant frequency. Box plots represent an average by strain bin before and after the PGA. The color version of this figure is available only in the electronic edition.

of shear-wave velocity (Fig. 6). The higher amplitude of the coseismic change resolved by the autocorrelation analysis reflects changes of shallower material just below the station rather than changes in the structure between the surface and borehole sensors. Using the ST provides 50 times higher temporal resolution (at the expense of larger computation time and storage). Calculations of ACF using the ST indicate $60 \%$ drops of shear-wave velocity in the subsurface, with additional details of the coseismic drop and follow up recovery. Higher time resolution computations show that the processes generating velocity changes in the subsurface material are not smooth. These variations may be related to fast rearrangement of material or fluid pore-pressure effects during the passage of strong motion.

Previous studies using earthquake data recorded by KiK-net stations found nonlinear soil response by comparing spectral ratios computed from weak and strong ground motion (Bonilla et al., 2011; Ohmachi and Tahara, 2011; Régnier et al., 2013). Wu and Peng (2011) calculated spectral ratios using moving time windows of records generated by the 2011 Tohoku earthquake and observed a decrease of the predominant frequency during the strongest ground shaking followed by partial recovery. Seismic interferometry and autocorrelation analyses have been used to monitor velocity changes before and after the occurrence of a large earthquake (Sawazaki et al., 2009; Nakahara, 2014; Sawazaki et al., 2016). Nakata and Snieder (2012) examined monthly and annual averages of near-surface shear-wave velocity in relation to rain and shear-wave splitting all over Japan through seismic interferometry of surface and borehole KiK-net records. Ohmachi and Tahara (2011) studied velocity changes of the Aratozawa dam having a clay core rockfill following the $2008 M_{\mathrm{w}} 6.9$ Iwate-Miyagi Nairiku earthquake. They estimated shear velocity changes in the dam's core using the mainshock and $1 \mathrm{yr}$ of aftershock data recorded at the crest and gallery of the structure and showed velocity variations as a function of shear strain induced in the dam and slow recovery with time. Federico et al. (2016) used seismic interferometry with moving time windows to estimate shear modulus changes on synthetics and observations associated with nonlinear media.

Velocity changes computed with $\mathrm{ACF}$, either using short time windows or the ST on single waveforms (rather than stacked data), provide higher resolution on temporal variations of properties than previous studies. This higher temporal resolution is essential for estimating better the amplitude of coseismic changes because laboratory experiments indicate that material recovery has $\log (t)$ dependency (e.g., Dieterich and Kilgore, 1996; Johnson and Jia, 2005) associated with very rapid early evolution. This implies that the estimated amplitudes of coseismic changes even with small timesteps are likely to be lower bounds of the true changes.

Physical models attempting to explain material degradation and recovery processes in soils and damaged rocks (e.g., Lyakhovsky et al., 1997, 2016; Lebedev and Ostrovsky, 2014; Snieder et al., 2016; Shokouhi et al., 2017) can benefit from 
more accurate short-time estimation of coseismic changes of the type given in this work. The velocity changes computed at the subsurface of station IBRH16 provide important in situ constraints on the response of shallow material to strong shaking. Traditional shear modulus degradation curves are obtained from quasi-static laboratory experiments on small and disturbed soil samples. The in situ results in Figures 39 on changes of seismic velocity, predominant period, and shear modulus reflect processes in the subsurface material during propagation of strong waves that are not included in laboratory experiments. These and related in situ results could be accounted for in improved estimates of site effects and seismic shaking hazard. For example, the use of average in situ shear modulus degradation curves as complementary information to laboratory results to compute site-specific seismic hazard, taking into account nonlinear site response.

\section{Conclusions}

The proposed techniques in this work allow high-resolution monitoring of coseismic velocity changes in the local subsurface underneath individual stations. Computations of the IRF and ACF in moving time windows provide great stability and good temporal resolution. The ST increases the time resolution to the level of the sampling rate of the record. This helps when clarifying details of the velocity changes. For the case study examined in this work associated with the $M_{\mathrm{w}} 9$ Tohoku earthquake, the IRF and ACF methods indicate $30 \%$ and $50 \%$ coseismic velocity reductions, respectively. The larger value provided by the autocorrelation corresponds to changes in shallower section of the borehole. The predominant frequency is anticorrelated with respect to the velocity changes, which is consistent with shallow phenomena.

Which method is the best? We cannot answer this question because it depends on what data are available and what resolution is needed. Therefore, we present these methods, their advantages, and warnings (higher dispersion when computing instantaneous ACF). We address these techniques not only to earthquake engineering studies but also to people working on material rheology in general. Thus, we leave the door open for possible applications and problems that may appear when using them.

In this study, the computed velocity changes allow us to correct the proxy estimation of shear deformation and provide in situ estimation of shear modulus degradation. The in situ results constitute important complementary contributions on dynamic properties of soils and damaged rocks to those provided by laboratory measurements. Such observations can be used to improve constitutive equations of material degradation and healing, dynamic site effects, and estimates of seismic shaking hazard.

\section{Data and Resources}

Time histories used in this study were collected from the KiK-net website (http://www.kyoshin.bosai.go.jp, last accessed February 2018) in Japan. The multitaper spectral analysis F90 library is version 4.2 (Prieto et al., 2009).

\section{Acknowledgments}

The study benefitted from discussions with Jean-Paul Ampuero, Celine Gélis, Fernando Lopez-Caballero, and Diego Mercerat. The authors to thank Jamie Steidl and two anonymous reviewers who helped greatly improve this work. L. F. B. and P. G. acknowledge support by the French RAP 2017 project about in situ evaluation of nonlinear soil behavior during strong ground motion. Y. B.-Z. acknowledges support from the National Science Foundation (Grant EAR-162061) and the Department of Energy (Award DE-SC0016520).

\section{References}

Bensen, G. D., M. H. Ritzwoller, M. P. Barmin, A. L. Levshin, F. Lin, M. P. Moschetti, N. M. Shapiro, and Y. Yang (2007). Processing seismic ambient noise data to obtain reliable broad-band surface wave dispersion measurement, Geophys. J. Int. 169, 1239-1260.

Bonilla, L. F., R. J. Archuleta, and D. Lavallée (2005). Hysteretic and dilatant behavior of cohesionless soils and their effects on nonlinear site response: Field data observations and modeling, Bull. Seismol. Soc. Am. 95, 2373-2395.

Bonilla, L. F., K. Tsuda, N. Pulido, J. Regnier, and A. Laurendeau (2011). Nonlinear site response evidence of K-NET and KiK-net records from the 2011 off the Pacific coast of Tohoku earthquake, Earth Planets Space 63, 785-789.

Brenguier, F., M. Campillo, T. Takeda, Y. Aoki, N. M. Shapiro, X. Briand, K. Emoto, and H. Miyake (2014). Mapping pressurized volcanic fluids from induced crustal seismic velocity drops, Science 345, 80-82.

Brenguier, F., N. M. Shapiro, M. Campillo, V. Ferrazzini, Z. Duputel, O. Coutant, and A. Nercessian (2008). Towards forecasting volcanic eruptions using seismic noise, Nature Geosci. 1, 126-130, doi: 10.1038/ngeo104.

Chandra, J., P. Guéguen, and L. F. Bonilla (2016). PGA-PGV $/ V_{S}$ considered as a stress-strain proxy for predicting nonlinear soil response, Soil Dynam. Earthq. Eng. 85, 146-160, doi: 10.1016/j.soildyn.2016.03.020.

Chandra, J., P. Guéguen, J. H. Steidl, and L. F. Bonilla (2015). In-situ assessment of the $G-\gamma$ curve for characterizing the nonlinear response of soil: Application to the Garner Valley Downhole Array (GVDA) and the Wildlife Liquefaction Array (WLA), Bull. Seismol. Soc. Am. 105, no. 2A, 993-1010, doi: 10.1785/0120140209.

Claerbout, J. F. (1968). Synthesis of a layered medium from its acoustic transmission response, Geophysics 33, no. 2, 264-269.

Cohen, L. (1989). Time-frequency distributions-A review, Proc. IEEE 77, 941-981.

Daneshvar, M. R., C. S. Caly, and M. K. Savage (1995). Passive seismic imaging using microearthquakes, Geophysics 60, 1178-1186.

Dieterich, J. H., and B. D. Kilgore (1996). Imaging surface contacts; power law contact distributions and contact stresses in quarts, calcite, glass, and acrylic plastic, Tectonophysics 256, 219-239.

Dresen, G., and Y. Gueguen (2004). Damage and rock physical properties, in Mechanics of Fluid Saturated Rocks, Y. Guéguen and M. Bouteca (Editors), International Geophysics Series, Vol. 89, Elsevier, New York, New York, 169-217.

Federico, D., L. F. Bonilla, and S. Foti (2016). In-situ shear modulus reduction computation using seismic interferometry by deconvolution from borehole and surface data: Theory and examples, Proc. 5th IASPEI/ IAEE International Symposium: Effects of Surface Geology in Seismic Motion, Taiwan, 15-17 August, Paper ESG5_00078.

Guéguen, P. (2016). Predicting nonlinear site response using spectral acceleration versus PGV/Vs30: A case history using the Volvi-Test site, Pure Appl. Geophys., doi: 10.1007/s00024-015-1224-5.

Guéguen, P., P. Johnson, and P. Roux (2016). Nonlinear dynamics induced in a structure by seismic and environmental loading, J. Acoust. Soc. Am. 140, no. 1, 582-590, doi: 10.1121/1.4958990. 
Hamiel, Y., V. Lyakhovsky, S. Stanchits, G. Dresen, and Y. Ben-Zion (2009). Brittle deformation and damage-induced seismic wave anisotropy in rocks, Geophys. J. Int. 178, 901-909, doi: 10.1111/j.1365-246X.2009.04200.x.

Hillers, G., Y. Ben-Zion, M. Campillo, and D. Zigone (2015). Seasonal variations of seismic velocities in the San Jacinto fault area observed with ambient seismic noise, Geophys. J. Int. 202, 920-932, doi: 10.1093/ gji/ggv151.

Iai, S., T. Morita, T. Kameoka, Y. Matsunaga, and K. Abiko (1995). Response of a dense sand deposit during 1993 Kushiro-Oki earthquake, Soils Found. 35, no. 1, 115-131.

Johnson, P. A., and X. Jia (2005). Nonlinear dynamics, granular media and dynamic earthquake triggering, Nature 473, 871-874.

Karabulut, H., and M. Bouchon (2007). Spatial variability and non-linearity of strong ground motion near a fault, Geophys. J. Int. 170, no. 1, 262274, doi: 10.1111/j.1365-246X.2007.03406.x.

Lebedev, A. V., and L. A. Ostrovsky (2014). A unified model of hysteresis and long-time relaxation in heterogeneous materials, Acoust. Phys. 60, no. $5,555-561$.

Lockner, D., J. Walsh, and J. Byerlee (1977). Changes in seismic velocity and attenuation during deformation of granite, J. Geophys. Res. 82, 5374-5378.

Lyakhovsky, V., Y. Ben-Zion, and A. Agnon (1997). Distributed damage, faulting, and friction, J. Geophys. Res. 102, 27,635-27,649.

Lyakhovsky, V., Y. Ben-Zion, A. Ilchev, and A. Mendecki (2016). Dynamic rupture in a damage-breakage rheology model, Geophys. J. Int. 206, 1126-1143, doi: 10.1093/gji/ggw183.

Lyakhovsky, V., Y. Hamiel, J. Ampuero, and Y. Ben-Zion (2009). Non-linear damage rheology and wave resonance in rocks, Geophys. J. Int. 178, 910-920.

Nakahara, H. (2014). Auto correlation analysis of coda waves from local earthquakes for detecting temporal changes in shallow subsurface structures: The 2011 Tohoku-Oki, Japan earthquake, Pure Appl. Geophys. 172, no. 2, 213-224, doi: 10.1007/s00024-014-0849-0.

Nakata, N., and R. Snieder (2012). Estimating near-surface shear wave velocities in Japan by applying seismic interferometry to KiK-net data, J. Geophys. Res. 117, no. B1, doi: 10.1029/2011JB008595.

Ohmachi, T., and T. Tahara (2011). Nonlinear earthquake response characteristics of a central clay core rockfill dam, Soils Found. 51, no. 2, 227-238.

Okada, Y., K. Kasahara, S. Hori, K. Obara, S. Sekiguchi, H. Fujiwara, and A. Yamamoto (2004). Recent progress of seismic observation networks in Japan-Hi-net, F-net, K-NET and KiK-net-, Earth Planets Space 56, xv-xxviii.

Oral, E., C. Gélis, L. F. Bonilla, and E. Delavaud (2017). Spectral element modelling of seismic wave propagation in visco-elastoplastic media including excess-pore pressure development, Geophys. J. Int. 211, 1494-1508.

Pasqualini, D., K. Heitmann, J. A. TenCate, S. Habib, D. Higdon, and P. Johnson (2007). Nonequilibrium and nonlinear dynamics in Berea and Fontainebleau sandstones: Low-strain regime, J. Geophys. Res. 112, no. B01204, doi: 10.1029/2006JB004264.

Pianese, G., B. Petrovic, S. Parolai, and R. Paolucci (2018). Identification of the nonlinear seismic response of buildings by a combined Stockwell transform and deconvolution interferometry approach, Bull. Earthq. Eng. 16, 3103-3126, doi: 10.1007/s10518-018-0307-y.

Poupinet, G., W. L. Ellworth, and J. Frechet (1984). Monitoring velocity variations in the crust using earthquake doublets: An application to the Calaveras fault, California, J. Geophys. Res. 89, 5719-5731.

Prieto, G. A., R. L. Parker, D. J. Thomson, F. L. Vernon, and R. L. Graham (2007). Reducing the bias of multitaper spectrum estimates, Geophys. J. Int. 171, 1269-1281.

Prieto, G. A., R. L. Parker, and F. L. Vernon (2009). A Fortran 90 library for multitaper spectrum analysis, Comput. Geosci. 35, 1701-1710, doi: 10.1016/j.cageo.2008.06.007.

Régnier, J., H. Cadet, L. F. Bonilla, E. Bertand, and J. Semblat (2013). Assessing nonlinear behavior of soil in seismic site response: Statistical analysis on KiK-net strong motion data, Bull. Seismol. Soc. Am. 103, no. 3, 1750-1770.
Remillieux, M. C., T. J. Ulrich, H. E. Goodman, and J. A. Ten Cate (2017). Propagation of a finite-amplitude elastic pulse in a bar of Berea sandstone: A detailed look at the mechanisms of classical nonlinearity, hysteresis, and non equilibrium dynamics, J. Geophys. Res. 122, 8892-8909, doi: 10.1002/2017JB014258.

Rivet, D., M. Campillo, N. M. Shapiro, V. Cruz-Atienza, M. Radiguet, N. Cotte, and V. Kostoglodov (2011). Seismic evidence of nonlinear crustal deformation during a large slow slip event in Mexico, Geophys. Res. Lett. 38, doi: 10.1029/2011GL047151.

Roux, P., and Y. Ben-Zion (2014). Monitoring fault zone environments with correlations of earthquake waveforms, Geophys. J. Int. 196, 10731081, doi: $10.1093 / \mathrm{gji} / \mathrm{ggt} 441$.

Sahu, S. S., G. Panda, and N. V. George (2009). An improved $S$-transform for time-frequency analysis, IEEE International Advance Computing Conference, Patiala, 315-319, doi: 10.1109/IADCC.2009.4809028.

Sawazaki, K., T. Saito, T. Ueno, and K. Shiomi (2016). Estimation of seismic velocity changes at different depths associated with the 2014 Northern Nagano Prefecture earthquake, Japan $\left(M_{\mathrm{W}} 6.2\right)$ by joint interferometric analysis of NIED Hi-net and KiK-net records, Progr. Earth Planet. Sci. 3, 36, doi: 10.1186/s40645-016-0112-7.

Sawazaki, K., H. Sato, H. Nakahara, and T. Nishimura (2006). Temporal change in site response caused by earthquake strong motion as revealed from coda spectral ratio measurement, Geophys. Res. Lett. 33, L21303, doi: 10.1029/2006GL027938.

Sawazaki, K., H. Sato, H. Nakahara, and T. Nishimura (2009). Time-lapse changes of seismic velocity in the shallow ground caused by strong ground motion shock of the 2000 Western-Tottori earthquake, Japan, as revealed from coda deconvolution analysis, Bull. Seismol. Soc. Am. 99, no. 1, 352-366.

Scherbaum, F. (1987). Seismic imaging of the site response using microearthquake recordings. Part II. Application to the Swabian Jura, southwest Germany, seismic network, Bull. Seismol. Soc. Am. 77, no. 6, 1924-1944.

Seggern, D. H., and J. G. Anderson (2017). Velocity change in the zone of a moderate $M_{\mathrm{w}} 5.0$ earthquake revealed by autocorrelations of ambient noise and by event spectra, Pure Appl. Geophys. 174, 1923-1935.

Sens-Schönfelder, C., and U. Wegler (2006). Passive image interferometry and seasonal variations of seismic velocities at Merapi volcano, Indonesia, Geophys. Res. Lett. 33, L21302, doi: 10.1029/2006GL027797.

Shokouhi, P., J. Rivière, R. A. Guyer, and P. A. Johnson (2017). Slow dynamics of consolidated granular systems: Multi-scale relaxation, Appl. Phys. Lett. 111, no. 25, 251604.

Snieder, R., A. Grêt, H. Douma, and J. Scales (2002). Coda wave interferometry for estimating nonlinear behavior in seismic velocity, Science 295, 2253-2255, doi: 10.1126/science.1070015.

Snieder, R., C. Sens-Schönfelder, and R. Wu (2016). The time dependence of rock healing as a universal relaxation process, a tutorial, Geophys. $J$. Int. 208, no. 1, 1-9.

Stockwell, R. G., L. Mansinha, and R. P. Lowe (1996). Localization of the complex spectrum: The S transform, IEEE Trans. Signal Process. 44, no. 4, 998-1001.

Todorovska, M. I., and M. Trifunac (2008). Impulse response analysis of the Van Nuys 7-storey hotel during 11 earthquakes and earthquake damage detection, Struct. Contr. Health Monit. 15, 90-116.

Wapenaar, K., E. Slob, R. Snieder, and A. Curtis (2010). Tutorial on seismic interferometry: Part 2-Underlying theory and new advances, Geophysics 75, no. 5, 75A211-75A227, doi: 10.1190/1.3463440.

Wapenaar, K., J. van der Neut, E. Ruigrok, D. Draganov, J. Hunziker, E. Slob, J. Thorbecke, and R. Snieder (2011). Seismic interferometry by crosscorrelation and by multidimensional deconvolution: A systematic comparison, Geophys. J. Int. 185, no. 3, doi: 10.1111/j.1365-246X.2011.05007.x.

Weaver, R. L., and O. I. Lobkis (2004). Diffuse fields in open systems and the emergence of the Green's function (L), J. Acoust. Soc. Am. 116, no. 5, 2731, doi: 10.1121/1.1810232.

Wu, C., and Z. Peng (2011). Temporal changes of site response during the $2011 M_{\mathrm{w}} 9.0$ off the Pacific coast of Tohoku earthquake, Earth Planets Space 63, 791-795. 
Wu, C., Z. Peng, and Y. Ben-Zion (2009). Non-linearity and temporal changes of fault zone site response associated with strong ground motion, Geophys. J. Int. 176, 265-278, doi: 10.1111/j.1365246X.2008.04005.x.

Wu, C., Z. Peng, and Y. Ben-Zion (2010). Refined thresholds for non-linear ground motion and temporal changes of site response associated with medium size earthquakes, Geophys. J. Int. 182, 1567-1576, doi: 10.1111/j.1365-246X.2010.04704.x.

Département GERS

Laboratoire Séismes et Vibrations

Université Paris Est - IFSTTAR

14-20 Boulevard Newton, Cité Descartes

77447 Marne-la-Vallée, Cedex 2

France

fabian.bonilla@ifsttar.fr

(L.F.B.)
Institut des Sciences de la Terre (ISTerre)

Université de Grenoble Alpes/CNRS/IFSTTAR/CS40700

38058 Grenoble, Cedex 9

France

philippe.gueguen@univ-grenoble-alpes.fr

(P.G.)

Department of Earth Sciences

University of Southern California

Los Angeles, California 90089-0740

benzion@usc.edu

(Y.B.-Z.)
Manuscript received 30 March 2018;

Published Online 15 January 2019 